\title{
Demand Forecasting of The Automobile Sales Using Least Square, Single Exponential Smoothing and Double Exponential Smoothing
}

\author{
Tresna Maulana Fahrudin ${ }^{1 *}$, Rysda Putra Ambariawan ${ }^{2}$, Made Kamisutara ${ }^{2}$ \\ ${ }^{1}$ Department of Data Science, Faculty of Computer Science, UPN "Veteran" Jawa Timur \\ Jl. Rungkut Madya No.1, Gn. Anyar, Kec. Gn. Anyar, Surabaya, Jawa Timur 60294 \\ ${ }^{2}$ Department of Informatics Engineering, Faculty of Computer Science, Universitas Narotama \\ Jl. Arief Rachman Hakim 51, Sukolilo, Surabaya, Jawa Timur 60117 \\ Email: ${ }^{1 *}$ tresna.maulana.ds@ upnjatim.ac.id; ${ }^{2}$ rysda.putra@gmail.com; ${ }^{2}$ made.kamisutara@ @arotama.ac.id \\ *Corresponding author
}

\begin{abstract}
Sales strategies require the right managerial in marketing products with the development of technology and communication, the decision making in product sales supported by complete data and can be analyzed into intelligence business solutions. The research discussed and provided solutions about how to forecast future demand targets from a set of data history by making a predictive model of product demand in the real case. The research study was obtained from automobile sales, which the company probably set the strategy from the forecast result of automobile sales by the system in the future. The research used forecasting methods such as Least Square, Single Exponential Smoothing, and Double Exponential Smoothing to achieve a small percentage of prediction error. The dataset was collected from Mitsubishi Motors Corporation which obtained 60 samples of popular product types such as Pajero, FE and L300 from 2014 to 2018 over a period of months. The experimental results reported that Double Exponential Smoothing has given a better performance than other methods. The forecasting result of Pajero reached the MAPE of 3.26\%, FE reached the MAPE of $3.24 \%$, and L300 reached the MAPE of 3.37\%. This study indicates that the selection of the forecasting method depends on the actual data pattern and the adjustment of the parameters in predicting future points.
\end{abstract}

Keywords: Business Intelligence; Forecasting; Automobile Sales; Least Square; Single Exponential Smoothing; Double Exponential Smoothing.

\section{Introduction}

Business Intelligence refers to the application, technology, process related to a set of stages beginning from data collection, data storage, data use, data disclosure, and data analysis to produce useful decision making. When asked to prioritize technology investments, Chief Information Officers (CIOs) rank Business Intelligence first, indicating its strategic significance. The efficiency and accuracy of business intelligence are critical factors in generating profits and losses in today's highly competitive environment. The advantages of using Business Intelligence have been emphasized by several researchers. By making decisions based on business analytics, organizations will enhance their business practices and efficiency (Gaardboe \& Svarre, 2018).

Business Intelligence is closely related to Big Data Analytics, which the data comes from high volumes, various type and fast process. The main components of Big Data Analytics include descriptive analytics, predictive analytics, and prescriptive analytics. The aim of descriptive analytics is to discover and describe the characteristics of entities and relationships between entities within the existing big data, while predictive analytics is to forecast the patterns or trends by addressing the problems to answer what will happen. On other hands, prescriptive analytics is to address the problems what we should do with the best outcome under uncertainty (Sun, Zou, \& Strang, 2015). Business intelligence allows combine stages in the process by engaging predictive analytics to forecast sales targets, stock and demand of the product.

The application of business intelligence has the potential to be applied in automobile sales, the most important factor is stock availability. An accurate forecast will assist the upstream suppliers' capacity and material planning. Furthermore, inventory requirements are directly linked to the errors between the forecast of demand over the lead-time and review period, and the actual realization of demand (Ali, Boylan, \& Syntetos, 2012). In the midst of globalizing competition, the automotive industry is becoming customer care oriented in its business model. In order to strengthen its competitiveness and 
improve the quality of the service offers, the automotive industry must understand consumer needs and recognize the importance of those needs in maintaining their enterprises (Chiu \& Shu, 2017).

One of the automobile sales companies in Indonesia as an authorized Mitsubishi dealer is PT. Sun Star Motor, a private company engaged in the automotive sector that was founded in 1974 (UD. Sun Motor). The company continues to grow every year, which it has 39 branches in 2019 with fluctuating demand. Data reports that the top sales were 1,208,019 units in 2014, but sales decreased to $16 \%$ with total sales of $1,013,291$ units in 2015. The company has achieved a slight increase in unit sales from 2015 to 2018, PT. Sun Star Motor redeemed several stocks of units from PT. Kramayudha Tiga Berlian as ATPM (Sole Agent Holder). The challenge is how to build a precise forecasting model to estimate the sales target of automobile units to customers based on historical demand.

In predicting the automobile sales target, the company still used the manual estimation method based on years to month (YTM) and Years to Years (YTY) calculations. The result is inaccurate predictions and difficult to be measured performance. Based on these explanations, we are interested in examining more deeply how to make sales forecasting of Mitsubishi products at PT Sun Star Motor Surabaya with Least Square, Single Exponential Smoothing and Double Exponential Smoothing. The forecasting of automobile sales based on historical demand for the near month to get useful information that various forecasting methods provide which it can give the business intelligence solution for the corporation.

Therefore, this research study aims to build a forecasting model for automobile sales of Mitsubishi motor products based on historical demand using the comparison of three methods, such as Least Square, Single Exponential Smoothing, and Double Exponential Smoothing. The best forecasting model is indicated by the performance of achieving the smallest MAPE (Mean Absolute Percentage Error) in both the training and testing set.

\section{Literature Review}

The literature review discussed related works consists of recent research studies in various field and application of business intelligence. The next discussion is about the fundamental theory of proposed forecasting methods and measurement of forecasting performance.

\subsection{Related Works}

Carmine (2018) proposed the research about business intelligence applied in small size for profit companies. The research explained that the term "Business Intelligence" refers to intelligent technology that can help businesses enhance their performance and increase the chances of survival and development. To apply business intelligence, several conditions are sometimes faced, such as an indication of lack of practicality related to its application in the daily life of the company. In addition, how to consider the size of the company, limited entrepreneurial competence and technology availability. The researcher was looking for alternatives to implementing business intelligence in small companies by considering two aspects, namely customer profitability and customer satisfaction levels. The objective of the research is how the companies achieve maximum results by using simple technology. The experiment result reported that the individual companies $(60 \%)$, the micro (35\%) has 2-9 staff, and small companies $(4,8 \%)$ has $10-49$ persons considered to make use the simple technology such as excel sheet or simple data processing which specific with organization needed (D'Arconte, 2018).

Karina et al. (2019) proposed the research about business intelligence for designing a restaurant marketing strategy. The research designed the marketing strategy for a cafe restaurant, which the targets were mid-low costumer. The key issue for the restaurant is no clear marketing plan has ever been implemented. Since they are not based on any strategy, the promotions that have been used so far are not targeted and have had little effect on sales. Restaurants should be able to forecast customer consumption trends using business intelligence tools like Power Business Intelligence (Power BI). Furthermore, Market Basket Analysis was used to model the demand pattern. With the 4P (Product, Location, Price, Promotion) concept, consumer consumption patterns were captured and used to design the best marketing strategy. Some of the restaurant menus were discovered to have a special relationship that could be used as a promotion to boost sales. Other findings include children and office workers in the segmented customer. Power BI dashboard supported the 
processing of all information to make it easier for the restaurant's executives for analyzing the sales change depending on the frequency of events and activities (Halim, Halim, \& Felecia, 2019).

Cempírek et al. (2021) proposed the research about the utilization of business intelligence tools in cargo control. The research discussed the utilization of Business Intelligence in a shipping company for controlling intermodal cargo. It consists of a Business Intelligence-based as well as brief guidelines for creating computer applications. When it comes to intermodal transportation, the application was used to monitor cargo of dedicated trains or other types of cargo. The experiment reported that the free MS Excel modules such as Power Query, Power Pivot, and DAX were ultimately better at working with data from dedicated trains. The application efficiently processes data regarding train intermodal transportation, and as a result, the implementation has an automated reporting method that was available online that allows analyzing the entire cargo relating to a container unit, train, all trains allocated for "roundtrip" (Václav, Gabriel, Blanka, Libor, \& Michal, 2021).

The explanation of the three research studies above, it is known that business intelligence is not only limited to technology, but also its application in various fields such as small size for profit companies, restaurant marketing strategy and intermodal cargo control. The output from the adoption of business intelligence provides different benefits for each field, benefits for customer profitability, customer satisfaction, consumer consumption patterns, and automated reporting. Therefore, business intelligence certainly gives the confidence to be applied in the field of automobile sales targets which will be discussed in the next chapter of this paper.

\subsection{Fundamental Theory}

The fundamental theory discussed the basic concept of forecasting, implementation of forecasting methods such as Least Square, Single Exponential Smoothing, Double Exponential Smoothing, and measurement of forecasting performance using mean absolute percentage error.

\footnotetext{
${ }^{1}$ Jebb AT, Tay L, Wang W and Huang Q (2015) Time series analysis for psychological research: examining and forecasting change. Front. Psychol. 6:727. doi: 10.3389/fpsyg.2015.00727
}

\subsubsection{Forecasting and Time Series}

Many companies utilize judgment forecasting methods depends on the knowledge of experienced employees and managers (Petropoulos, Kourentzes, Nikolopoulos, \& Siemsen, 2018). Forecasting is the process of estimating how the series of observations will continue into the future (Hyndman \& Athanasopoulos, 2014). Forecasting is a technique for predicting future based on testing conditions in the past. Forecasting, in general can be classified into two types, namely subjective forecasting and objective forecasting. Subjective forecasting is a prediction that puts more emphasis on decisions obtained from the discussion results, personal opinion and intuition (looks less scientific) but expecting to give good results. On the other hand, objective forecasting is a prediction that by following mathematical and statistical rules in showing the relationship between demand and one or more variables that influence it (Sun, et al., 2020).

Based on the period of forecasting, forecasting is classified into three types, namely short-term, medium-term, and long-term forecasting. Short-term forecasting has span up to less than three months, generally used to work scheduling, planning purchases, workforce levels, and production levels. Medium-term forecasting has span up from less than three months to three years, generally used for production planning, budgeting, sales planning, and analyzing various operating plans. Long-term forecasting has to span up more than three years, generally used to plan new products, capital expenditures, expansion, and research and development (Dmitry, Tsipoulanidis, \& Schönberger, 2019).

Data patterns that are often used in time series refer to data that has been collected, recorded, or observed regarding an event changes over time. The pattern of movement is when data moves over a certain period of time and tends to a direction, either up or down. The data patterns in the form of time series such as cycles, seasonality, random variations, and trends ${ }^{1}$.

\subsubsection{Least Square}

Carl F. Gauss (mathematician and physicist) discovered Least Square method in the 17th century. This method is still useful in forecasting, especially for determining the linear relationship between two variables. Least Square method is based on the concept of minimizing the squares 
deviation number (Dengen, et al., 2018). The formula of Least Square method following the equation (1).

$$
Y=a+b X
$$

Where

$Y=$ the estimated trend value in time period

$a=$ the intercept $Y$ if $X=0$

$b=$ the slope trend line

$X=$ the time period (daily, weekly, monthly or yearly)

Before calculating $Y$ of Least Square method, it needs to complete $a$ and $b$ variables. $a$ is intercept ( $Y$-axis) and $b$ is linear curve slope, while to find $a$ and $b$ variables following equation (2) and (3):

$$
\begin{aligned}
& a=\frac{\sum Y}{n} \\
& b=\frac{\sum X Y}{\sum X^{2}}
\end{aligned}
$$

Equation (2) uses $n$ variable which is the amount of data, it is related to determine $X$ value in Least Square. The alternative is divided into two groups, if the amount of data is even, then $X$ value is $[\ldots,-5,-3,-1,1,3,5, \ldots]$. While if the amount of data is odd, then $X$ value is $[\ldots,-3,-2$, $1,0,1,2,3, \ldots]$.

\subsubsection{Single Exponential Smoothing}

Single Exponential Smoothing is used for short-term forecasting. The model assumes that the data fluctuates around a fixed average value or approximately horizontal, with no trends or growth patterns (Nazim \& Afthanorhan, 2014). Single Exponential Smoothing uses a smoothing constant that ranges from 0 to 1 as a weight value close to the value of current and previous observations. The weight value is close to 1 have a greater emphasis on the current value, whereas the weight value is close to 0 have an emphasis on the previous data point (Mas-Machuca, Sainz, \& Martinez-Costa, 2014). The formula of Single Exponential Smoothing is defined by the following equation (4).

$$
S_{t}=\alpha X_{t}+(1-\alpha) S_{t-1}
$$

To build a forecasting model is require the previous observations in any time period $t . S_{t}$ is the forecast on the period $t, X_{t}$ is the actual or observation of time series on the period $t$, and $S_{t-1}$ is the previous forecast on the period $t-1$. The critical process is when determining the number of smoothing constants which is defined by $\alpha$, where $0<\alpha<1$ and $t \geq 3$. To gain the optimal $\alpha$ generally done by trial and error to determine the lowest error value. The drawback of Single Exponential Smoothing is will fail to work well in dynamic changes in the real case when facing the pattern of observation is random, trend, and seasonal variation (Asogwa, Eze, \& Okonkwo, 2019) (Ostertagov'A \& Ostertag, 2012). The model ignores the ups and downs of random variation and seeing the smoother line on the graph, but it generates forecasts that lag behind the observed trend.

\subsubsection{Double Exponential Smoothing}

There are alternative methods of the exponential smoothing model which can handle the observation in trend and growth pattern, such as Brown's and Holt's Double Exponential Smoothing (DES). Both can solve issues when dealing with difficulty predict the actual data in trend patterns and random variance, as well as solve the drawbacks of single exponential smoothing. Brown's DES uses different smoothing constants to make the trend and slope smoother, while Holt's DES uses two smoothing constants $\alpha$ and $\beta$ to adjust the trend and slope rates flexibly (Nazim \& Afthanorhan, 2014). Holt's DES is essentially the same as Brown's DES (Hyndman, Koehler, Ord, \& Snyder, 2008), but Holt's DES uses two components, are exponentially smoothed series following equation (5), and trend estimation following equation (6).

$$
S_{t}^{\prime}=\alpha X_{t}+(1-\alpha)\left({S^{\prime}}_{t-1}+T_{t-1}\right)
$$

Where $\boldsymbol{S}_{\boldsymbol{t}}^{\prime}$ does not only calculate the exponential smoothing dependent on the current observation $\boldsymbol{X}_{\boldsymbol{t}}$ and the previous exponentially smoothed series $\boldsymbol{S}_{\boldsymbol{t}-\mathbf{1}}$, but also calculates the previous trend estimation $\boldsymbol{T}_{\boldsymbol{t}-\mathbf{1}}$. The variable of $\boldsymbol{S}_{t-1}^{\prime}$ and $\boldsymbol{T}_{\boldsymbol{t}-1}$ must be calculated previously to use equation (5) and (6), these values are not available when $\boldsymbol{t}=\mathbf{1}$. Therefore, it must be determined $\boldsymbol{S}_{t-\mathbf{1}}^{\prime}$ and $\boldsymbol{T}_{\boldsymbol{t}-\mathbf{1}}$ is equal to $\boldsymbol{X}_{\mathbf{1}}$ at the beginning of the period.

$$
T_{t}=\beta\left(S^{\prime}{ }_{t}-S^{\prime}{ }_{t-1}\right)+(1-\beta) T_{t-1}
$$

Holt's DES allows the model to adjust the trend and slope rate flexibly, where $\mathbf{0}<\boldsymbol{\alpha}<1$ and $\mathbf{0}<\boldsymbol{\beta}<1$ (Bose, Dey, Roy, \& Sarddar, 2019).

$$
F_{t+m}=S_{t}^{\prime}+T_{t} m
$$


To forecast the next period $t$ following the equation (7), where $F_{t+m}, m$ is the period number of a step ahead. The next forecast is the summation between exponentially smoothed series $S_{t}^{\prime}$ and the product of the trend estimation $T_{t}$ and the period number of a step ahead $m$.

\subsubsection{Mean Absolute Percentage Error (MAPE)}

Mean Absolute Percentage Error (MAPE) is the measurement of forecasting performance that calculates the percentage error between the observed data and the forecast result. MAPE calculates the absolute error of each period obtained from the subtracting between the observation data and the forecast results, then divided by the observation data (Kim \& Kim, 2016). MAPE result indicates the mean of absolute percentage, the formula of MAPE following the equation (8).

$$
M A P E=\left(\frac{100 \%}{n}\right) \sum_{t=1}^{n} \frac{[X t-F t]}{X t}
$$

Where $X t$ is actual data in period $t, F t$ is forecast result in period $t$, and $n$ is total data. Table 1 shows MAPE criteria which it is classifying into 4 classes.

Table 1. MAPE Criteria

\begin{tabular}{cc}
\hline MAPE & Category of Forecast \\
\hline$<10 \%$ & Very Good \\
$10 \%-20 \%$ & Good \\
$20 \%-50 \%$ & Reasonable \\
$>50 \%$ & Bad \\
\hline
\end{tabular}

\section{Methods}

This section discussed the research system design of business intelligence technique for forecasting automobile sales, including population and samples, data collection methods and processes. In addition, it will discuss the forecasting model such as Least Square, Single Exponential Smoothing, and Double Exponential Smoothing. These methods are an important part of the business intelligence web-based application that has been built. The business intelligence application is not only used to input automobile sales data such as the type, time period, and historical demand but also forecasting methods are embedded into the application to analyze the historical demand data and predict the customer's future demand. The model will be evaluated by mean absolute percentage error as the forecasting performance measurement. The evaluation scenario is divided into two stages, namely the training and testing set. The research system design was illustrated in Figure 1.

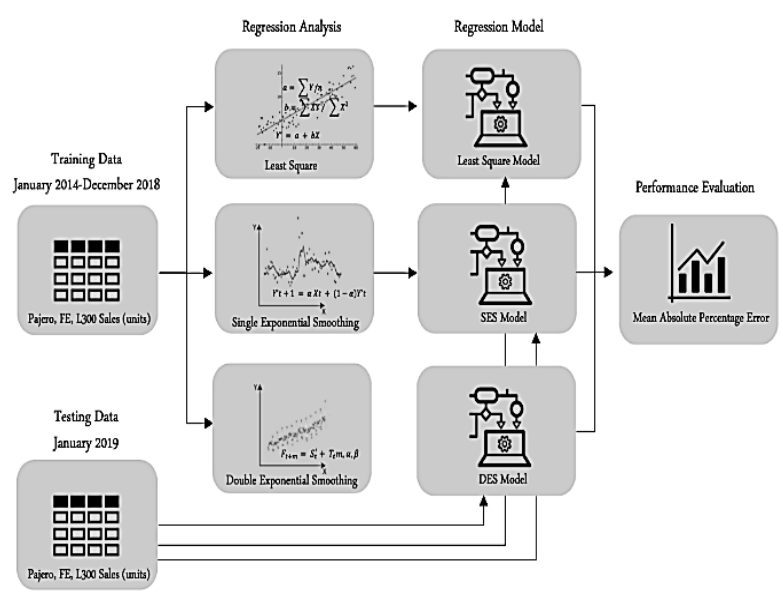

Figure 1. System Design of Business Intelligence Technique for Forecasting The Automobile Sales

Data collection in this research was obtained directly from PT. Sun Star Motor (Surabaya). The dataset was taken starting from January 2014 to December 2018, especially Mitsubishi motor product type sales such as Pajero, L300 and FE, which are exported from ERP software dms.sunmotor.co.id. If its views from the usability of the product, Pajero is a for the family car, L300 is for a cargo car and the FE is for a box truck. Figure 2 illustrates the dataset of Mitsubishi motor product sales (Pajero, FE, L300) from 2014-2018 in line chart. The chart shows that the sales of the product were quite fluctuated, there is no significant up or down trend. The sales outcomes of each type of product were competitive every month. In fact, the data with fluctuation patterns make it more difficult to make a forecast model, because the majority of regression models usually face actual data patterns that have an up or down trend.

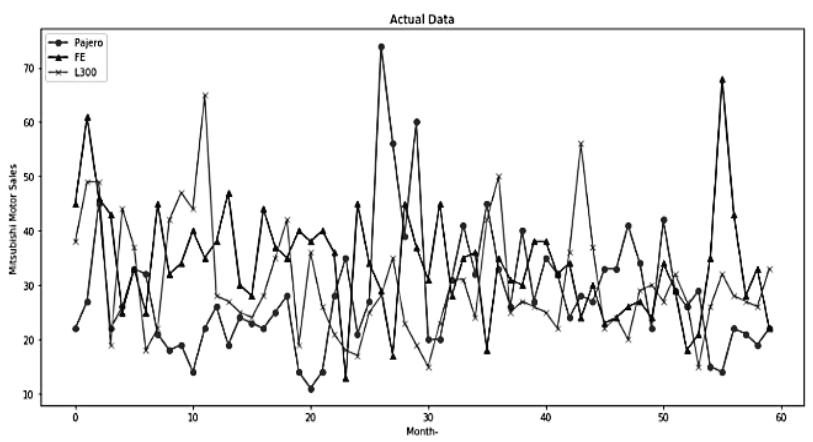

Figure 2. The Dataset of Mitsubishi Motor Product Sales (Pajero, FE, L300) from 2014-2018 
Figure 3 illustrates the sales of Mitsubishi motor product based on type in the annual period. The company has successfully sold 301 units of Pajero, 464 units of FE, and 474 units of L300 in 2014. The company saw sales drop Mitsubishi Motor's overall sales in 2015, such as 269 units of Pajero, 426 units of FE, and 329 units of L300. The sales of Pajero increased $73.23 \%$ (466 units) in 2016, while both FE and L300 getting drop only sold 400 units and 313 units respectively. The company saw sales drop again for two product types in 2017, 379 units of Pajero and 365 units of FE, while L300 increased $18.21 \%$ (370 units). The sales of FE and L300 increased 382 and 332 units respectively, while Pajero getting drop only sold 295 units. It shows that sales of Mitsubishi motor products have fluctuated, a certain strategy is needed to answer this challenge. However, this research tries to build a forecasting model that fits the actual data patterns and utilizes the model to predict the number of future sales targets, then a strategy to increase product sales can be carried out.

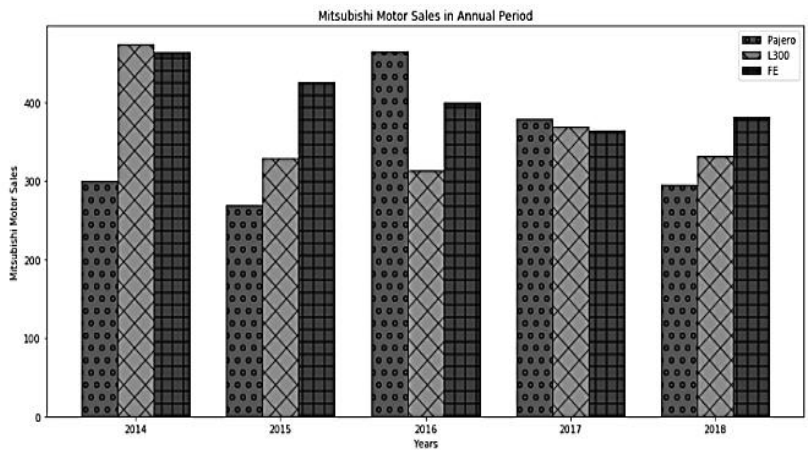

Figure 3. The Sales of Mitsubishi Motor Product in The Annual Period

\section{Results}

This section discussed the performance evaluation of the forecasting model using Least Square, Single Exponential, and Holt's Double Exponential Smoothing. The experiment divided into two scenarios, training set and testing set. The training set used the sales of Mitsubishi automobile from January 2014 to December 2018, while the testing set used the sales of Mitsubishi automobile in January 2019. The performance evaluation measurement based on Mean Absolute Percentage Error (MAPE) would have chosen the best model of regression analysis which the forecasting model fit with historical or actual data.

\subsection{Performance Evaluation of Forecasting Model using Least Square}

The first scenario was using a training set, the experiment involved the sales of Mitsubishi automobile dataset from January 2014 to December 2018. Least Square was applied as the model of regression analysis in the research, which the number of samples was 60 months. It means the amount of data is even and set the $X$ variable $=[\ldots,-5,-3,-1,1,3,5, \ldots]$. Figure 4 shows the intersection point between actual data and forecast results in Least Square Model. It can be seen that the least square generates a model that forms a straight line (with a slight slope), but does not fit the actual data. The model is not able to predict the actual data in the training scenario, many prediction points are inaccurate.

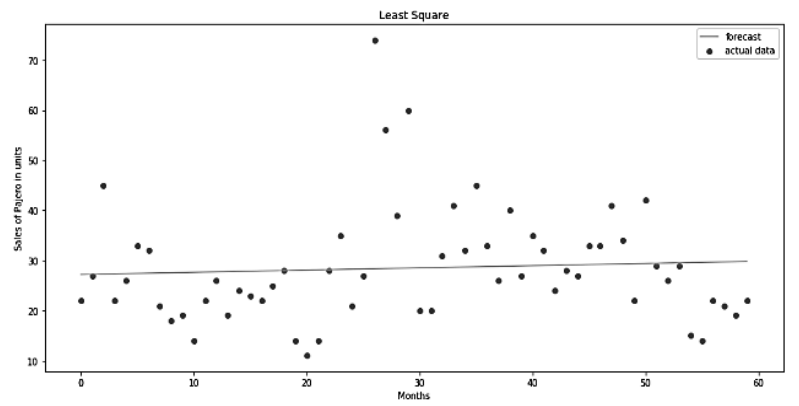

Figure 4. The Forecasting Model of Mitsubishi Motor Product Sales from January 2014-December 2018 using Least Square

Table 2 shows the MAPE of Mitsubishi motor product sales using Least Square. The training data of all product type was fluctuated, while Least Square built the forecasting model in a straight line with a slight slope. The forecasting model that is formed still does not represent the actual data conditions. Least Square given quite a good performance in the training set with MAPE for Pajero 32.04\%, L300 28.22\%, and FE 22.90\%. However, if it is seen from the feasibility of the generating model, it does not meet the criteria to be applied as the alternative model for the testing set because will generate inaccurate forecasts. The testing set shows the performance of Least Square which predicted the sales target of Pajero 30 units, L300 26 units and FE 29 units in January 2019.

Table 2. MAPE of Mitsubishi Motor Product Sales using Least Square

\begin{tabular}{ccc}
\hline Product Type & Training Set & Testing Set \\
\hline Pajero & $32.04 \%$ & $29.84237288 \sim 30$ units \\
L300 & $28.22 \%$ & $25.54067797 \sim 26$ units \\
FE & $22.90 \%$ & $28.59830508 \sim 29$ units \\
\hline
\end{tabular}




\subsection{Performance Evaluation of Forecasting Model using Single Exponential Smoothing}

Single Exponential Smoothing needs to be adjusted to the optimal $\alpha$ (alpha) parameter to obtain the smallest MAPE. The $\alpha$ parameter set beginning from 0.1 to 1 , while to gain the optimal $\alpha$ generally done by trial and error to determine the lowest error value. Single Exponential Smoothing was applied as the model of regression analysis, which optimal $\alpha$ parameter set $=0.3$. Figure 5 shows the intersection point between actual data and forecast results using Single Exponential Smoothing. Despite the fact that the intersection points look like they were close together, the forecast line was still not precise enough to match the actual data pattern.

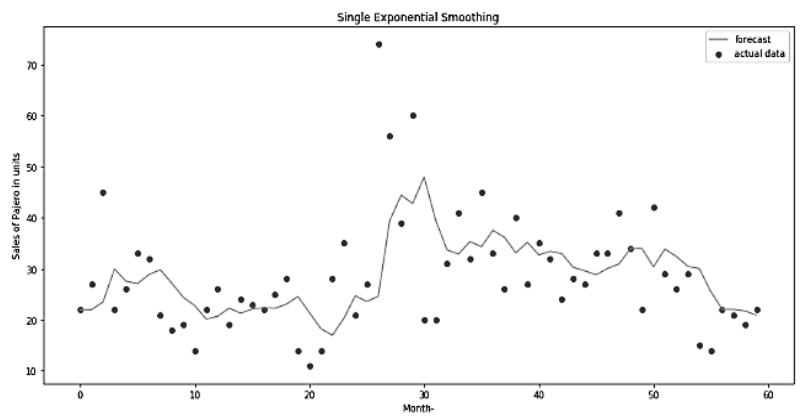

Figure 5. The Forecasting Model of Mitsubishi Motor Product Sales from January 2014 - December 2018 using Single Exponential Smoothing

Table 3 shows the MAPE of Mitsubishi motor product sales using Single Exponential Smoothing. The method built the forecasting model an up and down line following actual data points although the training data of all product type has fluctuated. Single Exponential Smoothing built a forecasting model that is more representative (see Figure 5) of actual data points than Least Square. In fact, Single Exponential Smoothing has given quite good performance in the training set with MAPE for Pajero $28.52 \%$, L300 $30.91 \%$, and FE $24.40 \%$ which is close to MAPE of Least Square. It means that the model also does not meet the criteria to be applied as the alternative model for the testing set because will generate inaccurate forecasts. The testing set shows the performance of Single Exponential Smoothing which predicted the sales target of Pajero 21 units, L300 29 units and FE 32 units in January 2019.
Table 3. MAPE of Mitsubishi Motor Product Sales using Single Exponential Smoothing

\begin{tabular}{ccc}
\hline Product Type & Training Set & Testing Set \\
\hline Pajero & $28.52 \%$ & $21.2397072 \sim 21$ units \\
L300 & $30.91 \%$ & $28.703312 \sim 29$ units \\
FE & $24.40 \%$ & $31.5659456 \sim 32$ units \\
\hline
\end{tabular}

\subsection{Performance Evaluation of Forecasting Model using Holt's Double Exponential Smoothing}

Single Exponential Smoothing only set $\alpha$ parameter to obtain the forecast result, while Holt's Double Exponential Smoothing both $\alpha$ and $\beta$ parameter. The advantage of the method has to adjust the trend and slope rates flexibly using these parameters. Figure 6 showed the intersection point between actual data and forecast results using Holt's Double Exponential Smoothing. The intersection points seem to be close together, and the forecast line followed the actual data pattern with great precision. The forecast result of the method is better than using Least Square and Single Exponential Smoothing.

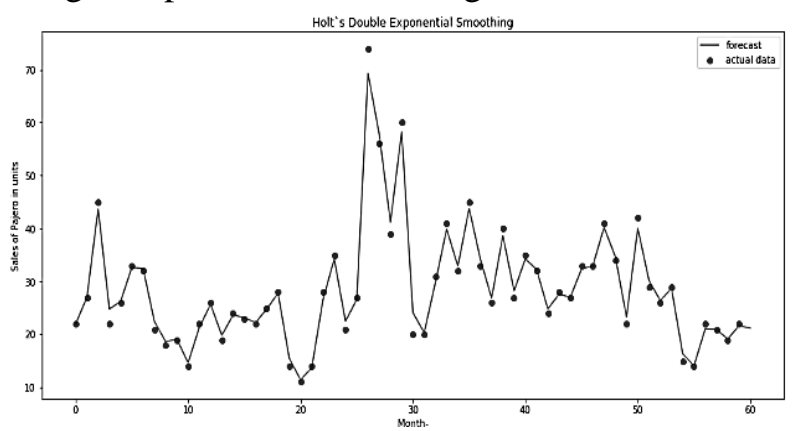

Figure 6. The Forecasting Model of Mitsubishi Motor Product Sales from January 2014-December 2018 using Holt's Double Exponential Smoothing

Table 4 shows the MAPE of Mitsubishi motor product sales using Holt's Double Exponential Smoothing. The minimum MAPE of the method was obtained using $\alpha$ and $\beta$ degree. Holt's Double Exponential Smoothing given the best performance in the training set with MAPE for Pajero $3.26 \%$, L300 $3.38 \%$, and FE 3.24\%. The method has a smaller MAPE than Least Square and Single Exponential Smoothing. It means that the model is feasible to be applied as the alternative model for the testing set because will generate accurate forecasts. The testing set shows the performance of Holt's Double Exponential Smoothing which predicted the sales target of 
Pajero 21 units, L300 33 units and FE 21 units in January 2019.

Table 4. MAPE of Mitsubishi Motor Product Sales using Holt's Double Exponential Smoothing

\begin{tabular}{ccc}
\hline Product Type & Training Set & Testing Set \\
\hline Pajero & $3.26 \%$ & $21,1922082 \sim 21$ units \\
L300 & $3.38 \%$ & $32,7690542 \sim 33$ units \\
FE & $3.24 \%$ & $20,6192091 \sim 21$ units \\
\hline
\end{tabular}

\section{Discussion}

The previous relevant research explained that the adoption of business intelligence provides different benefits for each field, benefits for customer profitability, customer satisfaction, consumer consumption patterns, and automated reporting. On other hand, the proposed research has certainly given the different way of research which combined the business intelligence technique and automobile sales targets. The summary of findings of the proposed research reported that one of three forecasting methods in the experiment given the best performance, feasible and reasonable to implement in automobile sales targets. The proposed research has proved to build a forecasting model that fitted the actual data patterns, the implication of the proposed research is how to utilize the model to predict the number of future automobile sales targets. It will give the company an advantage to determine the right stock of automobile type each month, reduce the risk of unsold stock items, and determine a strategy to increase product sales.

However, the implementation of the forecasting method in each different case will use a different method because it will be affected by the pattern of observation which is random, trend, and seasonal variation. In addition, there is a limited ability of the exponential smoothing method group in predicting future values, it is only able to predict one step. If it is continued to multistep prediction, the prediction value may trend up or down making it imprecise. This is influenced by the larger number representation of months or years and the variable value of the resulting forecasting model equation. Therefore, it is necessary to use a method that can work dynamically following the observed data patterns and be able to predict the multi-step.

\section{Conclusions}

The conclusion of the proposed research in the implementation of business intelligence for forecasting automobile sales following:
1. The proposed research is how business intelligence technique useful for forecasting automobile sales and utilize the model for predicting the sales target in the future.

2. The population and samples of Mitsubishi automobile product sales were quite fluctuated, the sales outcomes of each type of product were competitive every month. In fact, the data with fluctuation patterns make it more difficult to make a forecast model, because the majority of regression models usually face actual data patterns that have an up or down trend.

3. The performance of three forecasting methods in the training set reported that Least Square given average MAPE of $27.72 \%$, Single Exponential Smoothing given MAPE of $27.94 \%$ and Holt's Double Exponential Smoothing given MAPE of $3.29 \%$.

4. Least Square is not feasible as the forecasting model because the generating of the forecasting model in a straight line with a slight slope, while the training data of all product type has fluctuated. On other hand, Single Exponential Smoothing using $\alpha$ parameter generated the intersection points look like between actual data and forecast close together, but the forecast line was still not precise enough to match the actual data pattern.

5. Holt's Double Exponential Smoothing using $\alpha$ and $\beta$ parameter given the best performance because the intersection points seem to be close together, and the forecast line followed the actual data pattern with great precision. The summary of findings of the proposed research reported that the method is feasible and reasonable to implement in automobile sales targets. It will give the company an advantage to determine the right stock of automobile type each month, reduce the risk of unsold stock items, and determine a strategy to increase product sales.

6. For further research, it is necessary to involve data samples from all types of Mitsubishi automobile product sales, the goal is that the benefits of the forecasting method can be used to obtain profits and the right automobile sales strategy.

\section{References}

Ali, M. M., Boylan, J. E., \& Syntetos, A. A. (2012). Forecast Errors and Inventory Performance Under Forecast Information Sharing. 
International Journal of Forecasting, 28(4), 830-841.

Asogwa, O. C., Eze, C. M., \& Okonkwo, C. R. (2019). Modeling the Cases of Road Traffic Crashes: A Case of Exponential Smoothing Approach. International Journal of Mathematics Trends and Technology, 65(1), 46-52.

Bose, R., Dey, R. K., Roy, S., \& Sarddar, D. (2019). Time Series Forecasting using Double Exponential Smoothing for Predicting the Major Ambient Air Pollutants. In Information and Communication Technology for Sustainable Development (pp. 603-613). Singapore: Springer.

Chiu, C., \& Shu, C.-H. (2017). Monthly Car Sales Prediction using Internet Word-of-Mouth (eWOM). 2017 IEEE International Conference on INnovations in Intelligent SysTems and Applications (INISTA). Gdynia, Poland: IEEE.

D'Arconte, C. (2018). Business Intelligence Applied in Small Size for Profit Companies. Procedia Computer Science, 131, 45-57.

Dengen, N., Haviluddin, Andriyani, L., Wati, M., Budiman, E., \& Alameka, F. (2018). Medicine Stock Forecasting Using Least Square Method. The 2nd East Indonesia Conference on Computer and Information Technology (EIConCIT) 2018 (pp. 100-103). South Sulawesi, Indonesia: IEEE.

Dmitry, I., Tsipoulanidis, A., \& Schönberger, J. (2019). Demand Forecasting: A DecisionOriented Introduction to the Creation of Value. Global Supply Chain and Operations Management, 11-124.

Gaardboe, R., \& Svarre, T. (2018). Business Intelligence Success Factors: A Literature Review. Journal of Information Technology Management, 29(1), 1-15.

Halim, K. K., Halim, S., \& Felecia. (2019). Business Intelligence for Designing Restaurant Marketing Strategy: A Case Study. Procedia Computer Science, 161, 615-622.

Hyndman, R. J., \& Athanasopoulos, G. (2014). Forecasting: Principles and Practice. University of Wester Australia: OTexts.
Hyndman, R. J., Koehler, A. B., Ord, J. K., \& Snyder, R. D. (2008). Forecasting with Exponential Smoothing. Berlin: SpringerVerlag Berlin Heidelberg.

Kim, S., \& Kim, H. (2016). A New Metric of Absolute Percentage Error for Intermittent Demand Forecasts. International Journal of Forecasting, 32, 669-679.

Mas-Machuca, M., Sainz, M., \& Martinez-Costa, C. (2014). A Review of Forecasting Models for New Products. Intangible Capital, 10(1), 125.

Nazim, A., \& Afthanorhan, A. (2014). A Comparison Between Single Exponential Smoothing (SES), Double Exponential Smoothing (DES), Holt's (Brown) and Adaptive Response Rate Exponential Smoothing (ARRES) Techniques in Forecasting Malaysia Population. Global Journal of Mathematical Analysis, 2(4), 276280.

Ostertagov'A, E., \& Ostertag, O. (2012). Forecasting Using Simple Exponential Smoothing Method. Acta Electrotechnica et Informatica, 12(3), 62-66.

Petropoulos, F., Kourentzes, N., Nikolopoulos, K., \& Siemsen, E. (2018). Judgmental Selection of Forecasting Models. Journal of Operations Management, 60, 34-46.

Sun, X., Huang, X.-Y., Gordon, C., Mittermaier, M., Beckett, R., Cheong, W. K., . . . Semple, A. (2020). A Subjective and Objective Evaluation of Model Forecasts of Sumatra Squall Events. Weather and Forecasting, 35(2), 489-506.

Sun, Z., Zou, H., \& Strang, K. (2015). Big Data Analytics as a Service for Business Intelligence. In: Janssen M. et al. (eds) Open and Big Data Management and Innovation. I3E 2015. Lecture Notes in Computer Science (Vol. 9373). Springer.

Václav, C., Gabriel, F., Blanka, K., Libor, K., \& Michal, T. (2021). Utilization of Business Intelligence Tools in Cargo Control. Transportation Research Procedia, 53, 212-223. 